\title{
Composição Bromatológica, Consumo e Digestibilidade In Vivo de Dietas com Diferentes Níveis de Feno de Catingueira (Caesalpinea bracteosa), Fornecidas para Ovinos Morada Nova ${ }^{1}$
}

\section{Severino Gonzaga Neto ${ }^{2}$, Ângela Maria Vieira Batista ${ }^{3}$, Francisco Fernando Ramos de Carvalho ${ }^{3}$, Rafael Leonardo Vargas Martínez ${ }^{4}$, José Elmy Arruda Simões Barbosa ${ }^{5}$, Elizabel Oliveira Silva ${ }^{5}$}

\begin{abstract}
RESUMO - Com objetivo de determinar o consumo e a digestibilidade in vivo, bem como a composição química de dietas com níveis crescentes $(0,50$ e 100\%) de feno de catingueira (FC), utilizaram-se 15 ovinos Morada Nova, durante um período de 22 dias. Foi usado delineamento inteiramente casualizado com três tratamentos e cinco repetições. OFC apresentou 91,5\% de matéria seca (MS), 93,89\% de matéria orgânica (MO), 11,25\% de proteína (PB), 4,31\% de extrato etéreo (EE), 45,47\% de fibra em detergente neutro (FDN), 37,08\% de fibra em detergente ácido (FDA), 8,39\% de hemicelulose (HE), 24,37\% de celulose (CE), 12,52\% de lignina e 6,30\% de tanino condensado. Os consumos de MO e MS, em g/dia, g/kg 0,75 e \%PV; energia bruta (EB), em kcal $/ \mathrm{kg} / \mathrm{dia}$ e $\mathrm{kcal} / \mathrm{kg}^{0,75}$; e dos componentes da parede celular foram reduzidos linearmente pelo aumento de FC na dieta. Os consumos de PB, proteína digestível (PD) e EE aumentaram linearmente com o aumento do FC na dieta. Os coeficientes de digestibilidade da MS, MO, PB e EB das dietas não foram afetados pela inclusão do FC. No entanto, observou-se redução linear para os coeficientes de digestibilidade da FDN, FDA, CEe EEe efeito quadrático para o coeficiente de digestibilidade da HE. Os consumos médios de MS e PB verificados nos níveis intermediários de FC atenderam as exigências de mantença dos animais.
\end{abstract}

Palavras-chave: capão, digestibilidade in vivo, exigências, pequeno ruminante, semi-árido, tanino

\section{Bromatological Composition, Intake and In Vivo Digestibility of the Diets with Different Levels of "Catingueira" Hay (Caesalpinea bracteosa), Fed to Morada Nova Sheep}

\begin{abstract}
Fifteen male castrated sheep were used during a period of 22 days to determine the bromatological composition, intake and in vivo digestibility of diets with increasing levels $(0,50$ and 100\%) of "catingueira" hay $(\mathrm{CH})$. A completely randomized experimental design with three treatment and five replications was used. "Catingueira" hay presented a 91.5\% dry matter (DM), 93.89\% organic matter (OM), $11.25 \%$ crude protein (CP), $4.31 \%$ ether extract (EE), $45.47 \%$ neutral detergent fiber (NDF), 37.08\% acid detergent fiber (ADF), $8.39 \%$ hemicellulose (HE), $24.37 \%$ cellulose (CE), $12.52 \%$ lignin, $1.86 \%$ silica and $6.30 \%$ condensed tannin. The increased CH levels in the diet linearly reduced the intakes of OM and DM (express in g/day, g/kg. ${ }^{.75}$ and \% LW), of gross energy (GE) (express in kcal $/ \mathrm{kg}^{\circ}$ day and kcal $/ \mathrm{kg}^{0,75}$ ) and of the cell wall components were. The intakes of CP, digestible protein (DP) and EE linearly increased as CH levels increased in the diet. The coefficients of digestibility of the DM, OM, CP and CE were not affected ed by inclusion of CH. However, a negative linear effect was observed for the coefficients digestibility of the NDF, ADF, CE and EE and a quadratic effect for the coefficient of digestibilities of HE. The average intake of DM and $\mathrm{CP}$ observed in the intermediate levels of $\mathrm{CH}$ attained the maintenance requirements of the animals.
\end{abstract}

Key Words: wether, in vivo digestibility, requirements, small ruminant, semi-arid, tannin

\section{Introdução}

A caatinga, vegetação predominante na região semi-árida do Nordeste, ocupa uma área de aproximadamente $900.000 \mathrm{~km} 2$, cerca de $10 \%$ do território nacional, constituindo-se na mais importante fonte de alimentação para os rebanhos desta região, chegando a participar em até $90 \%$ da dieta de caprinos e ovinos. Porém, devido à má distribuição das chuvas, geral- mente concentradas em 3 a 4 meses do ano, os rebanhos tornam-se bastante vulneráveis à estacionalidade da produção de forragem, deixando os produtores locais sem muitas alternativas alimentares, tornando a produção de alimentos um dos maiores desafios durante os meses de estiagem.

Durante o período chuvoso, normalmente há abundância de forragem. No período seco, porém, o material herbáceo remanescente é drasticamente

\footnotetext{
1 Parte da Dissertação do primeiro autor, realizada com apoio do IPA/CAPES/UFRPE.

2 Pós-Graduando em Produção AnimalUnesp-Jaboticabal-Via de Acesso Prof.Paulo D. Castellane, Km5, CEP.14.870-000. E-mail:gonzaga@fcav.unesp.br

3 Professor do DZO/UFRPE - Rua D. Manoel de Medeiros s/n - Dois Irmãos - Recife, PE - 50.000-000. E.mail: ramosff@elogica.com.br; baid@uol.com.br

${ }^{4}$ Mestre em Produção Animal - BUPESA - Recife, PE. E.mail: rafaelmartinezz@yahoo.com.br

5 Aluno do Curso de Graduação em Zootecnia/UFRPE, Bolsista PIBIC-CNPq/UFRPE.
} 
reduzido, restando para os animais apenas a biomassa das árvores e arbustos. Por outro lado, pouco se sabe acerca do valor nutritivo e manejo dessas forrageiras arbóreas e arbustivas, o que, indubitavelmente, tem levado à não utilização racional de muitas espécies de valor forrageiro.

A catingueira (Caesalpinea bracteosa) é a espécie de potencial forrageiro da caatinga que mais demora a entrar em dormência, mantendo-se com sua folhagem por aproximadamente 238 dias após o término das chuvas, embora seu máximo valor nutritivo ocorra na fase que coincide com a maior disponibilidade de forragem da região semi-árida (ARAÚJO FILHO et al., 1998).

Nos últimos anos, a pesquisa tem se voltado para estudos com muitas espécies da caatinga. No entanto, não tem havido uma preocupação em determinar as quantidades máximas que devem ser oferecidas aos animais. Portanto, o objetivo deste trabalho foi avaliar a composição química, o consumo e os coeficientes de digestibilidade in vivo de dietas com diferentes níveis de feno de catingueira.

\section{Material e Métodos}

O experimento foi conduzido no galpão de digestibilidade da sede da Empresa Pernambucana de Pesquisa Agropecuária-IPA, localizada na cidade do Recife-PE.

Foram utilizados 15 ovinos da raça Morada Nova, provenientes da Estação Experimental de Sertânea, pertencente ao IPA. Os animais, todos machos, castrados e vermifugados, foram pesados, após 12 horas de jejum, no início e no final do experimento, apresentando peso vivo médio inicial de $24,52 \mathrm{~kg}$ e peso vivo médio final de $24,86 \mathrm{~kg}$. Os animais foram sorteados para os tratamentos e alojados em gaiolas de metabolismo equipadas com cochos, bebedouros e receptores de fezes e urina, onde permaneceram por 22 dias.

As dietas foram compostas de feno de catingueira - FC (Caesalpinea bracteosa) e feno de capim-deplanta - FCP (Brachiaria purpurascens). A composição química dos fenos foi determinada no Laboratório de Nutrição Animal da UFRPE, segundo procedimentos descritos por SILVA (1990), e encontra-se na Tabela 1. O tanino foi determinado pelo método Folin-Denis, descrito por MAGALHÃES et al. (1997).

O FC foi preparado na Estação Experimental de Sertânea, pertencente ao IPA, e confeccionado com material na fenofase de frutificação, sendo composto por folhas e galhos finos.
O delineamento experimental utilizado foi o inteiramente casualizado com três tratamentos $(0,50 \mathrm{e}$ $100 \%$ de FC) e cinco repetições por tratamento, utilizando-se o seguinte modelo matemático:

$$
\mathrm{Y}_{\mathrm{ij}}=\mu+\mathrm{T}_{\mathrm{i}}+\mathrm{x}_{\mathrm{ij}}
$$

em que $Y_{i j}$ é variável dependente; $\mu$, média geral das observações; $\mathrm{T}_{\mathrm{i}}$, efeito do nível de feno de catingueira; $\mathrm{x}_{\mathrm{ij}}$, erro experimental associado à observação $\mathrm{Y}_{\mathrm{ij}}$.

As análises estatísticas dos dados foram realizadas com o auxílio do Programa SANEST - Sistema de Análises Estatísticas (ZONTA e MACHADO, 1991), por meio do qual submeteram-se todos os dados à análise de regressão.

Em virtude de o percentual de proteína bruta do FCP $(5,8 \%)$ ter se apresentado abaixo do percentual mínimo exigido para um ótimo desempenho dos microrganismos do rúmen, adicionou-se uréia nas dietas com 0 e $50 \%$ FC na proporção de $0,5 \%$ da MS do FCP.

O experimento teve duração de 22 dias, constituído de período de adaptação e período de coleta. O período de adaptação teve duração de 15 dias, com o intuito de adaptar os animais às novas condições de ambiente, manejo e alimentação, como também proporcionar excreção total do resíduo da alimentação anterior. Nesta fase, os animais receberam água e sal mineral, à vontade. $\mathrm{O}$ feno de catingueira foi adicionado à ração de forma gradativa juntamente com o feno de capim-de-planta.

Durante a fase de adaptação, efetuou-se o ajuste da oferta, proporcionando, inicialmente, $30 \%$ de sobras e no final desta fase, apenas $20 \%$ para todos os animais.

O período de coleta teve duração de sete dias e compreendeu a coleta total de fezes, bem como amostragem diária do material ofertado e das sobras, por animal.

Diariamente, as rações experimentais foram pesadas com base no consumo do dia anterior acrescidas de $20 \%$, fornecidas em duas porções diárias, às 8 e às $15 \mathrm{~h}$. Na ocasião, foram feitas as pesagens e anotações das quantidades de sobras e fezes, tomando-se quantidades de amostras correspondente a $10 \%$ do total diário para posterior análise da composição química, segundo metodologia de SILVA (1990).

As variáveis analisadas foram: consumo e digestibilidade da matéria seca (MS), matéria orgânica (MO), proteína bruta (PB), energia bruta (EB), fibra em detergente (FDN), fibra em detergente ácido (FDA), celulose (CE), hemicelulose (HE), matéria mineral(MM) e extrato etéreo (EE), além de consumo de proteína digestível (PD), energia digestível (ED) e energia metabolizável (EM), todas analisadas isoladamente, em função do nível de inclusão do feno de catingueira. 
Rev. bras. zootec.

Tabela 1 - Composição bromatológica dos fenos de catingueira (FC) e de capim-de-planta (FCP), em porcentagem da matéria seca

Table 1 - Chemical composition of the "catingueira" hay (Caesalpinea bracteosa) and of plant grass hay (Brachiaria purpurascens) in percentage of dry matter

\begin{tabular}{|c|c|c|}
\hline $\begin{array}{l}\text { Parâmetros } \\
\text { Parameters }\end{array}$ & $\begin{array}{c}\mathrm{FC} \\
\text { "Catingueira" hay }\end{array}$ & $\begin{array}{c}\text { FCP } \\
\text { Plant grass hay }\end{array}$ \\
\hline Matéria orgânica (\%) & 93,89 & 92,27 \\
\hline Organic matter & & \\
\hline Matéria mineral (\%) & 6,11 & 7,73 \\
\hline $\begin{array}{l}\text { Mineral matter } \\
\text { Proteína bruta (\%) }\end{array}$ & 11,25 & 5,80 \\
\hline Crude protein & & \\
\hline $\begin{array}{l}\text { Proteína digestível (\%) } \\
\text { Digestible protein }\end{array}$ & 7,39 & 3,71 \\
\hline Extrato etéreo (\%) & 4,31 & 1,94 \\
\hline $\begin{array}{l}\text { Ether extract } \\
\text { Energia bruta (kcal/kg MS) }\end{array}$ & 4507,91 & 4047,20 \\
\hline Gross energy ( $k c a l / k g$ DM) & & \\
\hline $\begin{array}{l}\text { Energia digestível }(\mathrm{kcal} / \mathrm{kg} \mathrm{MS}) \\
\text { Digestible energy }(\mathrm{kcal} / \mathrm{kg} \text { DM) }\end{array}$ & 2052,45 & 1767,41 \\
\hline $\begin{array}{l}\text { Fibra em detergente neutro (\%) } \\
\text { Neutral detergent fiber }\end{array}$ & 45,47 & 74,82 \\
\hline $\begin{array}{l}\text { Fibra em detergente ácido (\%) } \\
\text { Acid detergent fiber }\end{array}$ & 37,08 & 49,29 \\
\hline $\begin{array}{l}\text { Hemicelulose (\%) } \\
\text { Hemicellulose }\end{array}$ & 8,39 & 25,53 \\
\hline Celulose (\%) & 24,37 & 34,63 \\
\hline Lignina $(\%)$ & 12,52 & 12,06 \\
\hline $\begin{array}{l}\text { NIDAn }^{1}(\%) \\
N A D F\end{array}$ & 0,57 & 0,26 \\
\hline $\begin{array}{l}\text { Tanino (\%) } \\
\text { Tannin }\end{array}$ & 6,30 & - \\
\hline
\end{tabular}

${ }^{1}$ Nitrogênio insolúvel em detergente ácido (Insoluble nitrogen in acid detergent).

\section{Resultados e Discussão}

A composição bromatológica das dietas experimentais apresenta-se na Tabela 2.

$\mathrm{O}$ teor de proteína bruta $(\mathrm{PB})$ do $\mathrm{FC}$, verificado neste trabalho, foi de $11,25 \%$. Este teor pode ser considerado baixo, quando comparado com $17,06 \%$ (BRAGA, 1960), 15,25\% (ARAÚJO FILHO e SILVA, 1994) e 14,4\% (ARAÚJO FILHO et al., 1998) para a mesma forrageira, porém foi semelhante aos valores de 11,70 e $11,81 \%$, encontrados por VASCONCELOS (1997) e LIMA (1996), respectivamente.

O estado fenológico de confecção do feno de catingueira neste estudo foi o de frutificação. Segundo ARAÚJO FILHO et al. (1998), o estrato lenhoso da caatinga sofre flutuações no valor nutritivo ao longo do ano. O FC na fenofase de vegetação plena, ou seja, após o início da brotação (estação chuvosa), pode apresentar teor de proteína bruta próximo a
$17 \%$, decrescendo para $15,60 \%$ na fenofase de floração, depois para $14,40 \%$ na fenofase de frutificação e finalmente cai para $11,20 \%$ na fenofase de dormência. Este último é determinado no restolho lenhoso, ou seja, nas folhas que caem por ocasião da senescência.

OFCP, utilizado como controle neste experimento, apresentou inicialmente 5,8\% de PB (Tabela 1). Segundo CARNEIRO e RODRIGUEZ (1996), níveis inferiores a 7,0\% de PB na dieta podem prejudicar a fermentação ruminal, bem como provocar balanço negativo de nitrogênio. Por isto, adicionou-se $0,5 \%$ de uréia em relação ao total de FCP nas dietas com 0 e $50 \%$ do $\mathrm{FC}$, as quais passaram a ficar com percentuais de 7,38 e $8,78 \%$ de $\mathrm{PB}$, respectivamente (Tabela 2). Essa iniciativa parece ter proporcionado duas situações diferentes: por um lado, observou-se melhor ajuste na oferta de PB entre as dietas. Porém, o fornecimento de nitrogênio prontamente disponível 
(uréia), nas dietas com 0 e $50 \%$ de FC, parece ter proporcionado equilíbrio no aproveitamento do alimento pelos microrganismos ruminais nas diferentes dietas experimentais, o que pode ter beneficiado aquelas com menor inclusão de FC.

O percentual de EE encontrado no FC foi $4,31 \%$, inferior aos valores de 7,10 e 7,29\%, verificados por BRAGA (1960) e VASCONCELOS (1997), respectivamente. Segundo Tamminga, citado por VASCONCELOS (1997), altos teores de lipídeos na ração podem causarefeitos deletérios sobre os microrganismos ruminais, principalmente, em ovinos, nos quais esse efeito é mais pronunciado, podendo afetar a digestão da fibra.
Os valores de FDN, FDA e lignina (Tabela 1) foram mais altos que os observados na mesma leguminosa por VASCONCELOS (1997), que foram 38,71; 21,48; e 8,25\%, respectivamente. ARAÚJO FILHO et al. (1998) encontraram percentual de lignina de $12,70 \%$, semelhante ao encontrado no presente trabalho na fase de frutificação.

$\mathrm{O}$ valor da concentração de tanino observado foi de $6,30 \%$, o qual pode ser considerado baixo, se comparado aos 18,59 e $9,10 \%$ de tanino total, determinados na mesma espécie por VASCONCELOS (1997) e ARAÚJO FILHO et al. (1998), respectivamente, embora esteja acima dos $4,0 \%$, concentração

Tabela 2 - Composição química das dietas experimentais com diferentes níveis de feno de catingueira (FC), em substituição ao feno de capim-de-planta (FCP)

Table 2 - Experimental diets chemical composition with different levels of "catingueira" hay $(\mathrm{CH})$ in replacement of the plant grass hay (PGH)

\begin{tabular}{|c|c|c|c|}
\hline \multirow[t]{2}{*}{$\begin{array}{l}\text { Parâmetro } \\
\text { Parameter }\end{array}$} & \multicolumn{3}{|c|}{$\begin{array}{c}\text { Nível de inclusão (\%) } \\
\text { Replacement level }\end{array}$} \\
\hline & $0 \mathrm{FC}$ & $50 \mathrm{FC}$ & $100 \mathrm{FC}$ \\
\hline \multirow{2}{*}{$\begin{array}{l}\text { Matéria seca }(\mathrm{MS})(\%) \\
\text { Dry matter }(D M)\end{array}$} & 88,00 & 89,75 & 91,50 \\
\hline & \multicolumn{3}{|c|}{$\begin{array}{c}\text { Dados expressos em \% MS } \\
\text { Data expressed in \% DM }\end{array}$} \\
\hline $\begin{array}{l}\text { DMMatéria orgânica }(\%) \\
\text { Organic matter }\end{array}$ & 92,27 & 93,08 & 93,89 \\
\hline $\begin{array}{l}\text { Matéria mineral }(\%) \\
\text { Mineral matter }\end{array}$ & 7,73 & 6,92 & 6,11 \\
\hline Proteína bruta (\%) & 7,38 & 8,78 & 11,25 \\
\hline $\begin{array}{l}\text { Crude protein } \\
\text { Proteína digestível (\%) }\end{array}$ & 4,72 & 5,57 & 7,39 \\
\hline $\begin{array}{l}\text { Digestible protein } \\
\text { Extrato etéreo }(\%)\end{array}$ & 1,94 & 3,13 & 4,31 \\
\hline $\begin{array}{l}\text { Ether extract } \\
\text { Energia bruta (kcal/kg MS) }\end{array}$ & $4.047,20$ & $4.230,31$ & $4.507,91$ \\
\hline $\begin{array}{l}\text { Gross energy }(\mathrm{kcal} / \mathrm{kg} \text { DM) } \\
\text { Energia digestível }(\mathrm{kcal} / \mathrm{kg} \mathrm{MS}) \\
\text { Digestible energy }(\mathrm{kcal} / \mathrm{kg} D M)\end{array}$ & $1.767,41$ & $1.904,91$ & $2.052,45$ \\
\hline Energia metabolizável (kcal/kg MS)* & $1.449,28$ & $1.562,03$ & $1.683,01$ \\
\hline $\begin{array}{l}\text { Metabolizable energy ( } \mathrm{kcal} / \mathrm{kg} \mathrm{DM}) \\
\text { Fibra em detergente neutro }(\%)\end{array}$ & 74,82 & 57,02 & 45,47 \\
\hline $\begin{array}{l}\text { Neutral detergentfiber } \\
\text { Fibra em detergente ácido }(\%)\end{array}$ & 49,29 & 43,19 & 37,08 \\
\hline $\begin{array}{l}\text { Acid detergent fiber } \\
\text { Hemicelulose }(\%) \\
\text { Hemicellulose }\end{array}$ & 25,53 & 13,83 & 8,39 \\
\hline $\begin{array}{l}\text { Celulose }(\%) \\
\text { Cellulose }\end{array}$ & 34,63 & 29,50 & 24,37 \\
\hline $\begin{array}{l}\text { Lignina }(\%) \\
\text { Lignin }\end{array}$ & 12,06 & 12,29 & 12,52 \\
\hline $\begin{array}{l}\text { Tanino }(\%) \\
\text { Tannin }\end{array}$ & - & 3,15 & 6,30 \\
\hline
\end{tabular}

* Estimada a partir da energia digestível (ED), considerando que a energia metabolizável corresponde a 82\% da ED (ARC, 1980).

${ }^{1}$ Nitrogênio insolúvel em detergente ácido.

* Estimated from the digestible energy (DE), considering that the metabolizable energy corresponds to $82 \%$ DE (ARC, 1980).

1 Insoluble nitrogen in acid detergent. 
que não provoca alterações no rúmen, principalmente de ovinos. Segundo REED (1995), altas concentrações de tanino em folhas de leguminosas diminuem acentuadamente o consumo por alterar a palatabilidade, além de afetar a digestibilidade da fibra pelas ligações formadas com enzimas bacterianas e/ou formação de complexos indigestíveis com carboidratos da parede celular. NARJISSE et al. (1995) afirmam que níveis de até 6\% de tanino não afetam a digestibilidade em ovinos, porém interferem no consumo, o que, segundo BARROS et al. (1997), é um dos fatores que afeta diretamente a digestibilidade. Acima desta concentração, NARJISSE et al. (1995) verificaram que a capacidade de fermentação do fluido ruminal foi marcadamente deprimida, principalmente em ovinos, espécie bastante sensível a esta substância.

Os dados relativos ao consumo de matéria seca (CMS) e matéria orgânica (CMO), expressos em gramas por dia (g/dia), em gramas por unidade de peso metabólico $\left(\mathrm{g} / \mathrm{kg}^{0,75}\right)$ e em porcentagem do peso vivo (\%PV), são apresentados na Tabela 3.

Observou-se efeito linear decrescente nos consumos de MS e MO com a inclusão do FC nas dietas, quando expressos em g/dia $(\mathrm{P}<0,05), \mathrm{g} / \mathrm{kg}^{0,75}(\mathrm{P}<0,01)$ e \%PV $(\mathrm{P}<0,01)$. Portanto, maior consumo de MS e MO foi observado na dieta que não havia FC.

Diversos fatores podem afetar a ingestão de MS pelos herbívoros, principalmente, em ruminantes. MERTENS (1992) considera a FDN como um dos principais fatores de controle do consumo de MS pelos ruminantes. No entanto, neste trabalho, o nível $0 \%$ apresentou maior teor de FDN $(74,82 \%)$ em relação ao nível 100\% de FC $(45,47 \%)$ (Tabela 2) e, mesmo assim, proporcionou maior ingestão de MS. Dois fatores podem explicar este resultado. Um deles seria o aumento na concentração de tanino, à medida que se aumentou a participação do FC nas dietas. A concentração máxima de tanino no nível mais alto de FC foi de 6,3\%, superando assim o limite crítico para ovinos, que, segundo REED (1995), é de 4,0\%. Outra explicação seria a maior proporção de FDA em relação à FDN, no nível 100\% FC $(81,55 \%)$ e, conseqüentemente, menor proporção de hemicelulose $(18,45 \%)$, quando comparado com os outros níveis. RESENDE e QUEIROZ (1994) afirmaram que, para uma mesma ingestão de FDN, a ingestão de FDA pode diferir, dependendo do conteúdo de hemicelulose da ração. Embora a fibra seja um dos fatores mais limitantes do consumo de MS, neste caso, o efeito mais provável parece ter sido do tanino.

O CMS expresso em $\mathrm{g} / \mathrm{kg}^{0,75} /$ dia no nível $100 \%$ de FC, aparentemente baixo $(45,86)$, foi semelhante ao valor de 44,30 observado por SILVA et al. (1998) com a mesma forrageira e superior ao observado para a jurema preta $(37,20)$ e a faveleira $(12,20)$, estudadas por esses autores. Esses resultados ainda foram superiores aos observados para o sabiá $(34,20)$ em estudo realizado por PEREIRA (1998), como também para o jucá $(13,90)$, o mororó $(8,74)$ e o sabiá $(13,65)$, estudados por VIEIRA et al. (1998), porém inferiores aos observados para a camaratuba $(66,18)$

Tabela 3 - Consumo de matéria seca (MS), matéria orgânica (MO), equações de regressão em função dos níveis (ŶY) de feno de catingueira (FC) e respectivos coeficientes de determinação $\left(r^{2}\right)$ e variação (CV)

Table 3 - Dry matter (DM) and organic matter (OM) intake, regression equations in function of the levels ( $\hat{\mathrm{Y}}$ ) of "catingueira" hay (CH) and respective determination coefficients $\left(r^{2}\right)$ and coefficient of variation $(\mathrm{CV})$

\begin{tabular}{|c|c|c|c|c|c|c|}
\hline \multirow[t]{2}{*}{$\begin{array}{l}\text { Variável } \\
\text { Variable }\end{array}$} & \multicolumn{3}{|c|}{$\begin{array}{l}\text { Nível de inclusão } \\
\text { Replacement level }\end{array}$} & \multirow[t]{2}{*}{$\begin{array}{l}\text { Equação de regressão } \\
\text { Regression equation }\end{array}$} & \multirow[t]{2}{*}{$\begin{array}{l}\mathrm{r}^{2} \\
(\%)\end{array}$} & \multirow[t]{2}{*}{$\begin{array}{l}\mathrm{CV} \\
(\%)\end{array}$} \\
\hline & $0 \mathrm{FC}$ & $50 \mathrm{FC}$ & $100 \mathrm{FC}$ & & & \\
\hline & \multicolumn{3}{|c|}{$\begin{array}{l}\text { Consumo de MS } \\
\text { DM intake }\end{array}$} & & & \\
\hline g/dia (g/day) & 680,7 & 662,8 & 510,1 & $\hat{\mathrm{Y}}=703,199-1,70624 * \hat{\mathrm{I}}$ & 82,8 & 15,8 \\
\hline $\mathrm{g} / \mathrm{kg}^{0}, 75$ & 62,0 & 59,4 & 45,9 & $\hat{\mathrm{Y}}=63,783-0,16100 * * \hat{\mathrm{I}}$ & 86,7 & 11,8 \\
\hline \multirow{2}{*}{$\% \mathrm{PV}(\% L W)$} & 2,8 & 2,6 & 2,1 & $\hat{\mathrm{Y}}=2,864-0,00730^{* *} \hat{\mathrm{I}}$ & 87,9 & 11,1 \\
\hline & \multicolumn{3}{|c|}{$\begin{array}{c}\text { Consumo de } \mathrm{MO} \\
\text { OM intake }\end{array}$} & & & \\
\hline g/dia (g/day) & 623,0 & 614,7 & 475,5 & $\hat{\mathrm{Y}}=644,752-1,47248 * \hat{\mathrm{I}}$ & 79,2 & 15,7 \\
\hline $\mathrm{g} / \mathrm{kg}^{0,75}$ & 56,7 & 55,1 & 42,8 & $\hat{\mathrm{Y}}=58,481-0,13934 * * \hat{\mathrm{I}}$ & 83,7 & 11,8 \\
\hline$\% \mathrm{PV}(\% L W)$ & 2,5 & 2,5 & 1,9 & $\hat{\mathrm{Y}}=2,626-0,00634 * * \hat{\mathrm{I}}$ & 85,2 & 11,1 \\
\hline
\end{tabular}

${ }^{*}, * *$ Significativo a 5 e $1 \%$ de probabilidade, respectivamente, pelo teste $\mathrm{t}$.

$*{ }^{*} *$ Significant at 5 and $1 \%$ of probability, respectively, by $t$ test. 
por ARAÚJO et al. (1997) e com a maniçoba $(75,81)$ por ARAÚJO et al. (1996), todos com ovinos.

Considerando a necessidade de CMS de $51,02 \mathrm{~g} / \mathrm{kg}^{0,75} /$ dia para a manutenção de ovinos com peso vivo médio de $25 \mathrm{~kg}$ (NRC, 1985; NAS, 1977), observa-se que o fornecimento de FC satisfaz essa exigência em níveis de até 79,3\% da dieta.

$\mathrm{Na}$ Tabela 4, encontram-se os resultados de consumo de proteína bruta (CPB), proteína digestível (CPD) e extrato etéreo (CEE), expressos em gramas por dia (g/dia) e $\mathrm{g} / \mathrm{kg}^{0,75}$.

$\mathrm{O} C P B$ não sofreu efeito $(\mathrm{P}>0,05)$ dos níveis do FC. Os CPB diários observados em todos os níveis apresentaram-se acima das exigências mínimas de mantença para ovinos com peso vivo de aproximadamente $25 \mathrm{~kg}$, que é de $31,8 \mathrm{~g} / \mathrm{dia}$ (NRC, 1985). Os dados indicam que os CPB nos níveis $0 \%(58,09 \mathrm{~g} / \mathrm{dia})$, $50 \%(64,40 \mathrm{~g} / \mathrm{dia})$ e $100 \%(67,28 \mathrm{~g} / \mathrm{dia})$ correspondem a 182,67; 202,51; e 211,57\% das exigências mínimas de mantença, respectivamente. Portanto, com base nessas informações, todos os níveis de inclusão de FC superaram as exigências em termos de $\mathrm{PB}$, com ênfase para o nível $100 \%$.

O CPB registrado para o nível mais alto de $\mathrm{FC}$ foi de $6,06 \mathrm{~g} / \mathrm{kg}^{0,75}$. Este resultado superou o valor de $5,65 \mathrm{~g} / \mathrm{kg}^{0,75}$ obtido por PEREIRA et al. (1998), com o feno do sabiá, entretanto apresentou-se inferior aos valores de $8,79 \mathrm{~g} / \mathrm{kg}^{0,75}$ observado para a orelha de onça (ARAÚJO et al., 1994), 7,24 g/kg ${ }^{0,75}$ para a maniçoba (ARAÚJO et al., 1996) e 15,18 g/kg0,75 para a camaratuba (ARAÚJO et al., 1997), todas forrageiras nativas da caatinga nordestina.

Para o CPD, observou-se o mesmo comportamento verificado para o CPB. De acordo com a NRC (1985), as exigências mínimas de mantença para ovinos com $25 \mathrm{~kg}$ de peso vivo é de $2,47 \mathrm{~g} / \mathrm{kg}^{0,75} / \mathrm{dia}$ de PD. Os animais que receberam rações com 0,50 e $100 \%$ FC consumiram, em média, 3,39; 3,66; e $3,99 \mathrm{~g}$ de $\mathrm{PD} / \mathrm{kg}^{0,75} / \mathrm{dia}$, respectivamente, correspondendo, portanto, a 137,25; 148, 18 e 161,54\% das exigências para mantença.

Segundo SEOANE et al. (1992), aumento no teor protéico da ração proporciona incremento no consumo e redução nesse teor provoca diminuição da digestão do conteúdo da parede celular. Como o teor de PB do feno de catingueira usado neste estudo foi relativamente baixo, este efeito não foi pronunciado, principalmente com relação ao consumo dos constituintes da parede celular, como pode ser observado na Tabela 5. Outros fatores, como por exemplo alignificação da matéria seca de espécies lenhosas da caatinga, como a catingueira, tornam a fibra pouco digerível.

Quanto ao consumo de extrato etéreo (CEE), observou-se efeito quadrático $(\mathrm{P}<0,01)$. Esse comportamento deve-se, provavelmente, aos teores apresentados nas dietas com base na MS (Tabela 2).

$\mathrm{Na}$ Tabela 6, encontram-se os resultados de consumo de energia bruta (CEB), energia digestível

Tabela 4 - Consumo de proteína bruta (PB), proteína digestível (PD), extrato etéreo (EE), equações de regressão, em função dos níveis (î) de feno de catingueira (FC), e respectivos coeficientes de determinação $\left(\mathrm{r}^{2}\right)$ e variação $(\mathrm{CV})$

Table 4 - Crude protein (CP), digestible protein (DP) ether extract (EE) intake, regression equations in function of the levels $(\hat{I})$ of "catingueira" hay $(\mathrm{CH})$ and respective coefficients of determination $\left(r^{2}\right)$ and variation $(\mathrm{CV})$

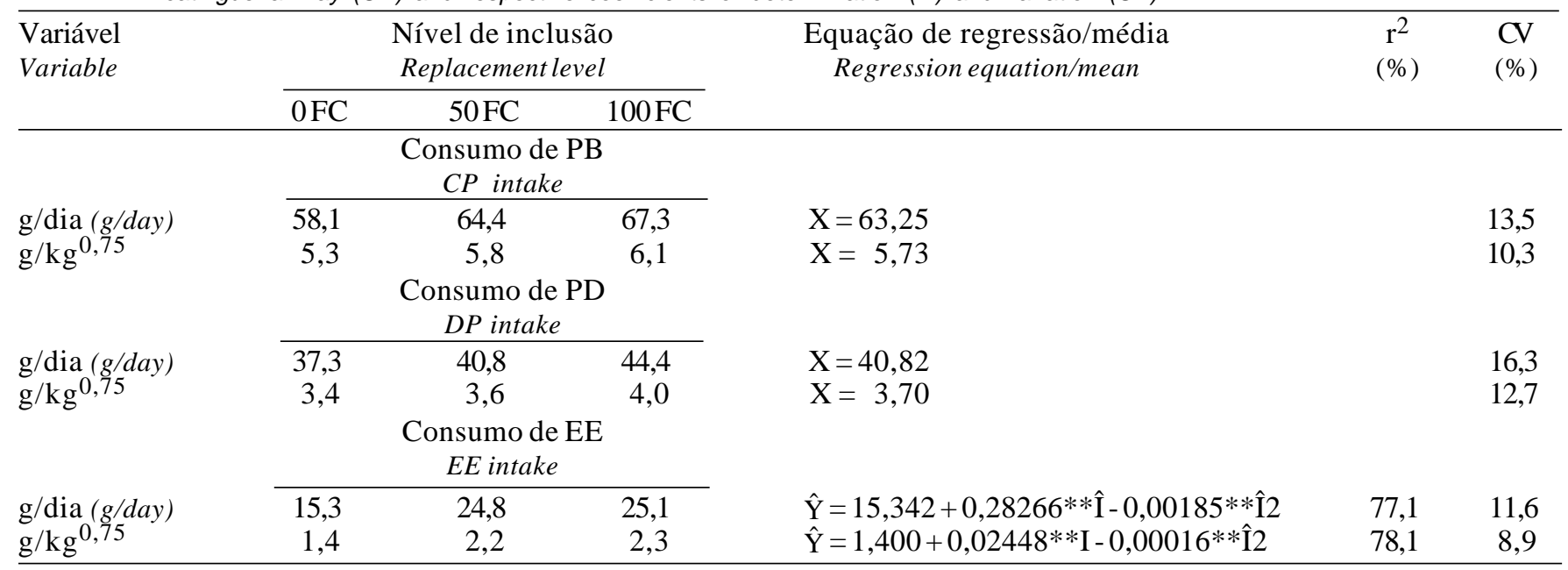

* Significativo a $5 \%$ de probabilidade, pelo teste $\mathrm{t}$.

* Significant at $5 \%$ of probability by $t$ test. 
(CED) e energia metabolizável (CEM), expressos em $\mathrm{kcal} / \mathrm{dia}$ e $\mathrm{kcal} / \mathrm{kg}^{0,75}$.

Considerando o consumo de energia (Tabela 6), não se observou efeito dos níveis do $\mathrm{FC}(\mathrm{P}>0,05)$ sobre os parâmetros estudados, exceto para o CEB, expresso em kcal $/ \mathrm{kg}^{0,75}$, que decresceu linearmente $(\mathrm{P}<0,05)$ com o aumento do nível de participação do FC. Para o CED, expresso em $\mathrm{kcal} / \mathrm{kg}^{0,75}$, verificaram-se valores médios de 110,$34 ; 113,02$; e 96,08, nos níveis 0,50 e $100 \%$ FC, respectivamente.

A exigência média de ED para mantença de ovinos com aproximadamente $25 \mathrm{~kg}$ de peso vivo, segundo NRC (1985), é de $199 \mathrm{kcal} / \mathrm{kg}^{0,75} /$ dia. Portanto, com base nessa informação, verifica-se déficit de ED na ordem de 44,$55 ; 43,21$; e $51,72 \%$, para os níveis 0,50 e $100 \%$ FC, respectivamente.

Os dados relativos ao consumo dos constituintes da fração fibrosa, exceto lignina, expressos em gramas por dia (g/dia) e em gramas por unidade tamanho metabólico $\left(\mathrm{g} / \mathrm{kg}^{0,75}\right)$, com base na porcentagem de matéria seca, encontram-se na Tabela 5 .

Observou-se efeito linear decrescente $(\mathrm{P}<0,01)$ para os consumos de todos os constituintes da fração fibrosa. Os máximos consumos desses constituintes ocorreram no nível 0\% de FC. Estes resultados podem ser explicados pela maior concentração de parede celular no nível $0 \%$ de FC, o que, naturalmente, proporcionou maior ingestão de FDN nesta dieta e, conseqüentemente, menor consumo na dieta com $100 \%$ FC. A FDN na dieta com $0 \%$ de FC foi de $74,82 \%$ contra $45,47 \%$ na dieta com nível mais alto de FC (Tabela 2). As frações menos digestíveis da parede celular, ou seja, celulose e lignina, como porcentagem da FDN, correspondem a 46,28 e 16,12, respectivamente ,no nível $0 \%$ de FC, contra 53,59 e 27,53 no nível $100 \%$ de FC. Naturalmente, a hemicelulose, fração normalmente mais digestível da parede celular, mostrou comportamento inverso, ou seja, correspondeu a 34,12 e $18,45 \%$ da FDN do nível 0 para o nível $100 \%$ FC, respectivamente. Com base nesses dados, pode-se inferir que o baixo consumo da fração FDN do feno de catingueira pode estar relacionado com o tipo de material ofertado, em que folhas e galhos finos eram misturados à ração, provocando maior rejeição de material mais lignificado. Este fato fica comprovado quando da menor digestibilidade desse material (Tabela 7).

Os níveis de tanino, apesar de estarem em níveis intermediários, podem ter afetado o consumo e a digestibilidade das diversas frações do alimento, prin-

Tabela 5 - Consumo da fibra em detergente neutro (FDN), fibra em detergente ácido (FDA), celulose (CE) e hemicelulose (HE), equações de regressão, em função dos níveis (Î) de feno de catingueira (FC), e respectivos coeficientes de determinação $\left(r^{2}\right)$ e variação (CV)

Table 5 - Neutral detergent fiber (NDF), acid detergent fiber (ADF), cellulose (CE), hemicellulose (HE) intake, regression equations, in function of the levels (I) of "catingueira" hay $(\mathrm{CH})$ and respective coefficients of determination $\left(r^{2}\right)$ and variation $(\mathrm{CV})$

\begin{tabular}{|c|c|c|c|c|c|c|}
\hline \multirow[t]{2}{*}{$\begin{array}{l}\text { Variável } \\
\text { Variable }\end{array}$} & \multicolumn{3}{|c|}{$\begin{array}{l}\text { Nível de inclusão } \\
\text { Replacement level }\end{array}$} & \multirow[t]{2}{*}{$\begin{array}{l}\text { Equação de regressão } \\
\text { Regression equation }\end{array}$} & \multirow[t]{2}{*}{$\begin{array}{l}\mathrm{r}^{2} \\
(\%)\end{array}$} & \multirow[t]{2}{*}{$\begin{array}{l}\mathrm{CV} \\
(\%)\end{array}$} \\
\hline & $0 \mathrm{FC}$ & $50 \mathrm{FC}$ & $100 \mathrm{FC}$ & & & \\
\hline & \multicolumn{3}{|c|}{$\begin{array}{l}\text { Consumo de FDN } \\
\text { NDF intake }\end{array}$} & & & \\
\hline $\begin{array}{l}\text { g/dia (g/day) } \\
\text { g/kg } 0,75\end{array}$ & $\begin{array}{r}494,3 \\
45,0\end{array}$ & $\begin{array}{l}\text { Consumo de FDA } \\
\text { ADF intake }\end{array}$ & $\begin{array}{r}210,2 \\
18,9 \\
A\end{array}$ & $\begin{array}{l}\hat{\mathrm{Y}}=496,912-2,84116 * * \hat{\mathrm{I}} \\
\hat{\mathrm{Y}}=45,297-0,26126 * * \hat{\mathrm{I}}\end{array}$ & $\begin{array}{l}99,9 \\
99,8\end{array}$ & $\begin{array}{l}18,5 \\
14,1\end{array}$ \\
\hline $\begin{array}{l}\mathrm{g} / \mathrm{dia}(\mathrm{g} / \mathrm{day}) \\
\mathrm{g} / \mathrm{kg}^{0,75}\end{array}$ & $\begin{array}{r}336,2 \\
30,6\end{array}$ & $\begin{array}{r}286,6 \\
25,7 \\
\text { nsumo } \\
C E \text { intc }\end{array}$ & $\begin{array}{r}185,7 \\
16,7 \\
\end{array}$ & $\begin{array}{l}\hat{\mathrm{Y}}=344,798-1,50530 * * \hat{\mathrm{I}} \\
\hat{\mathrm{Y}}=31,283-0,13936 * * \hat{\mathrm{I}}\end{array}$ & $\begin{array}{l}96,3 \\
97,2\end{array}$ & $\begin{array}{l}17,4 \\
13,0\end{array}$ \\
\hline $\begin{array}{l}\mathrm{g} / \mathrm{dia}(\mathrm{g} / \mathrm{day}) \\
\mathrm{g} / \mathrm{kg}^{0,75}\end{array}$ & $\begin{array}{r}238,6 \\
21,7\end{array}$ & $\begin{array}{l}\text { Consumo de HE } \\
\text { HE intake }\end{array}$ & $\begin{array}{r}120,3 \\
10,8 \\
\end{array}$ & $\begin{array}{l}\hat{\mathrm{Y}}=244,667-1,18248 * * \hat{\mathrm{I}} \\
\hat{\mathrm{Y}}=22,184-0,10906 * * \hat{\mathrm{I}}\end{array}$ & $\begin{array}{l}96,9 \\
97,7\end{array}$ & $\begin{array}{l}18,8 \\
14,1\end{array}$ \\
\hline $\begin{array}{l}\text { g/dia }(g / \text { day }) \\
\mathrm{g} / \mathrm{kg}^{0,75}\end{array}$ & $\begin{array}{r}158,1 \\
14,4\end{array}$ & $\begin{array}{r}74,2 \\
6,6\end{array}$ & $\begin{array}{r}34,4 \\
3,1\end{array}$ & $\begin{array}{l}\hat{\mathrm{Y}}=150,728-1,23642 * * \hat{\mathrm{I}} \\
\hat{\mathrm{Y}}=13,687-0,11302 * * \hat{\mathrm{I}}\end{array}$ & $\begin{array}{l}95,9 \\
95,6\end{array}$ & $\begin{array}{l}23,1 \\
16,9\end{array}$ \\
\hline
\end{tabular}

** Significativo a $1 \%$ de probabilidade, pelo teste $\mathrm{t}$.

** Significant at $1 \%$ of probability, by test $t$. 
cipalmente, a fração fibrosa, nos níveis mais elevados de FC.

Os coeficientes de digestibilidade aparente de matéria seca (DMS), matéria orgânica (DMO), proteína bruta (DPB), extrato etéreo (DEE) e energia bruta (DEB), expressos em percentagem, são apresentados na Tabela 7.

Os coeficientes de digestibilidade da MS, MO, PB e EB não foram influenciados $(\mathrm{P}>0,05)$ pelos níveis de inclusão do FC. Embora tenha se verificado maior teor de PB no nível mais alto de FC, essa superioridade não foi manifestada em nenhum dos coeficientes de digestibilidade das frações estudadas. A adição de uréia (nitrogênio prontamente disponível para os microrganismos) nas dietas com $0 \mathrm{e}$ $50 \%$ de FC talvez tenha proporcionado equilíbrio entre as dietas, mas não suficientes para melhorar os coeficientes de digestibilidade das diversas frações.

Tabela 6 - Consumo de energia bruta (EB), energia digestível (ED) e energia metabolizável (EM), equações de regressão em função dos níveis (Î) de feno de catingueira (FC), e respectivos coeficientes de determinação $\left(r^{2}\right)$ e variação $(C V)$

Table 6 - Gross energy (CE), digestible energy (DE), metabolizable energy (ME) intake, regression equations ,in function of the levels ( $(\hat{I})$ of "catingueira" hay $(\mathrm{CH})$, and respective coefficients of determination $\left(r^{2}\right)$ and variation $(\mathrm{CV})$

\begin{tabular}{|c|c|c|c|c|c|c|}
\hline \multirow[t]{2}{*}{$\begin{array}{l}\text { Variável } \\
\text { Variable }\end{array}$} & \multicolumn{3}{|c|}{$\begin{array}{l}\text { Nível de inclusão } \\
\text { Replacement level }\end{array}$} & \multirow[t]{2}{*}{$\begin{array}{c}\text { Equação de regressão } \\
\text { Regression equation }\end{array}$} & \multirow[t]{2}{*}{$\begin{array}{l}\mathrm{R}^{2} \\
(\%)\end{array}$} & \multirow[t]{2}{*}{$\begin{array}{l}\mathrm{CV} \\
(\%)\end{array}$} \\
\hline & $0 \mathrm{FC}$ & $50 \mathrm{FC}$ & $100 \mathrm{FC}$ & & & \\
\hline & \multicolumn{3}{|c|}{$\begin{array}{c}\text { Consumo de EB } \\
\text { EC intake }\end{array}$} & & & \\
\hline g/dia (g/day) & 58,1 & 64,4 & 67,3 & $X=63,25$ & & 13,5 \\
\hline $\begin{array}{l}\text { Kcal/dia } \\
\text { Kcal/day }\end{array}$ & 2756,4 & 2809,7 & 2394,9 & $X=2.653,70$ & & 15,9 \\
\hline $\mathrm{Kcal} / \mathrm{kg}^{0,75}$ & \multicolumn{3}{|c|}{$\begin{array}{l}\text { Consumo de ED } \\
\text { DE intake }\end{array}$} & $\hat{\mathrm{Y}}=258,011-0,40984 * \hat{\mathrm{I}}$ & 73,4 & 11,7 \\
\hline $\begin{array}{l}\text { Kcal/dia } \\
\text { Kcal/day }\end{array}$ & 1216,7 & 1261,4 & 1070,3 & $X=1.182,78$ & & 20,2 \\
\hline $\mathrm{Kcal} / \mathrm{kg}^{0,75}$ & \multicolumn{3}{|c|}{$\begin{array}{l}\text { Consumo de } \mathrm{EM}^{2} \\
\quad M E \text { intake } \\
\end{array}$} & $X=106,48$ & & 16,6 \\
\hline $\begin{array}{l}\text { Kcal/dia } \\
\text { Kcal/day }\end{array}$ & 968,9 & 1034,3 & 877,6 & $X=966,28$ & & 21,0 \\
\hline $\mathrm{Kcal} / \mathrm{kg}^{0,75}$ & 89,4 & 92,7 & 78,8 & 86,95 & & 17,5 \\
\hline
\end{tabular}

* Significativo a $5 \%$ de probabilidade pelo teste t.

2 Estimada a partir da energia digestível (ARC, 1980).

* Significant at $5 \%$ of probability by $t$ test.

2 Estimated from the digestible energy (ARC, 1980).

Tabela 7 - Coeficientes de digestibilidade aparente (D) da matéria seca (MS), matéria orgânica (MO), proteína bruta (PB), extrato etéreo (EE) e energia bruta (EB), equações de regressão, em função dos níveis (I) de feno de catingueira (FC), e respectivos coeficientes de determinação $\left(r^{2}\right)$ e variação $(C V)$

Table 7 - Apparent digestibility coefficient of dry matter (DM), organic matter (OM), crude protein (CP), ether extract (EE), gross energy $(C E)$, regression equations in function of the levels $(\hat{I})$ of "catingueira" hay $(\mathrm{CH})$ and respective coefficients of determination $\left(r^{2}\right)$ and variation $(\mathrm{CV})$

\begin{tabular}{|c|c|c|c|c|c|c|}
\hline \multirow[t]{2}{*}{$\begin{array}{l}\text { Variável } \\
\text { Variable }\end{array}$} & \multicolumn{3}{|c|}{$\begin{array}{l}\text { Nível de inclusão } \\
\text { Replacement level }\end{array}$} & \multirow[t]{2}{*}{$\begin{array}{l}\text { Equação de regressão/média } \\
\text { Regression equation/mean }\end{array}$} & \multirow[t]{2}{*}{$\begin{array}{l}\mathrm{r}^{2} \\
(\%)\end{array}$} & \multirow[t]{2}{*}{$\begin{array}{l}\mathrm{CV} \\
(\%)\end{array}$} \\
\hline & $0 \mathrm{FC}$ & $50 \mathrm{FC}$ & $100 \mathrm{FC}$ & & & \\
\hline $\operatorname{MS}(D M)$ & 47,6 & 50,5 & 50,2 & $X=49,43$ & & 7,0 \\
\hline $\mathrm{MO}(O M)$ & 49,4 & 51,9 & 51,9 & $X=51,07$ & & 6,8 \\
\hline $\mathrm{PB}(C P)$ & 64,0 & 63,4 & 65,7 & $X=64,39$ & & 5,9 \\
\hline $\mathrm{EE}(E E)$ & 50,5 & 35,6 & 13,8 & $\hat{\mathrm{Y}}=51,692-0,36720 * * \hat{\mathrm{I}}$ & 98,8 & 27,3 \\
\hline $\mathrm{EB}(C E)$ & 43,7 & 45,0 & 45,5 & $X=44,74$ & & 8,0 \\
\hline
\end{tabular}

** Significativo a $1 \%$ de probabilidade, pelo teste $\mathrm{t}$.

** Significant at $1 \%$ of probability by $t$ test. 
Rev. bras. zootec.

Tabela 8 - Coeficientes de digestibilidade da fibra em detergente neutro (FDN), fibra em detergente ácido (FDA), celulose (CE) e hemicelulose (HE), equações de regressão, em função dos níveis (Î) de feno de catingueira (FC), e respectivos coeficientes de determinação $\left(\mathrm{r}^{2}\right)$ e variação $(\mathrm{CV})$

Table 8 - Coefficients of digestibilidade (D) of the neutral detergent fiber (NDF), acid detergent fiber (ADF), cellulose (CE), hemicelulose $(\mathrm{HE})$, regression equations, in function of the levels (i) of "catingueira" hay $(\mathrm{CH})$, and respective determination coefficients $\left(r^{2}\right)$ and coefficient of variation (CV)

\begin{tabular}{|c|c|c|c|c|c|c|}
\hline \multirow{2}{*}{$\begin{array}{l}\text { Variável } \\
\text { Variable }\end{array}$} & \multicolumn{3}{|c|}{$\begin{array}{l}\text { Nível de inclusão repla } \\
\text { Replacement level }\end{array}$} & \multirow[t]{2}{*}{$\begin{array}{l}\text { Equação de regressão } \\
\text { Regression equation }\end{array}$} & \multirow[t]{2}{*}{$\begin{array}{l}\mathrm{r}^{2} \\
(\%)\end{array}$} & \multirow[t]{2}{*}{$\begin{array}{l}\mathrm{CV} \\
(\%)\end{array}$} \\
\hline & $0 \mathrm{FC}$ & $50 \mathrm{FC}$ & $100 \mathrm{FC}$ & & & \\
\hline $\begin{array}{l}\text { FDN } \\
N D F\end{array}$ & 49,1 & 41,7 & 32,6 & $\hat{\mathrm{Y}}=49,408-0,16484 * * \hat{\mathrm{I}}$ & 99,6 & 12,1 \\
\hline $\begin{array}{l}\text { FDA } \\
A D F\end{array}$ & 51,6 & 50,5 & 46,2 & $\hat{\mathrm{Y}}=52,169-0,05388 * \hat{\mathrm{I}}$ & 89,6 & 6,4 \\
\hline $\begin{array}{l}\text { CECE } \\
\text { HFHF }\end{array}$ & $\begin{array}{l}58,8 \\
438\end{array}$ & 55,4 & 47,7 & $\hat{\mathrm{Y}}=59,492-0,11086 * * \hat{\mathrm{I}}$ & 95,0 & 4,8 \\
\hline
\end{tabular}

${ }^{*},{ }^{* *}$ Significativo a 5 e $1 \%$ de probabilidade, respectivamente, pelo teste $\mathrm{t}$.

$*,{ }^{* *}$ Significant at 5 and $1 \%$ of probability, respectively, by $t$ test.

Com relação a DEE, observou-se decréscimo linear $(\mathrm{P}<0,01)$, à medida que se aumentou o FC nas rações. Os animais que receberam dietas com maiores proporções do FC, mesmo ingerindo maiores quantidades de extrato etéreo, não digeriram eficientemente este componente. De acordo com Tamminga, citado por VASCONCELOS (1997), os ovinos apresentam maior sensibilidade a níveis mais altos de EE na ração. Logo, o CEE diário no nível mais alto de FC foi equivalente a $4,89 \%$ do CMS, bem próximo do valor crítico para ovinos, que é de 5,0\% de EE em relação ao consumo total de MS.

Os coeficientes de digestibilidade dos constituintes da fração fibrosa são apresentados na Tabela 8 .

Observou-se efeito linear decrescente $(\mathrm{P}<0,01)$ dos níveis de inclusão de FC sobre os coeficientes de digestibilidade da FDN, FDA e CE e efeito quadrático $(\mathrm{P}<0,01)$ para a digestibilidade da HE. Alguns fatores parecem estar relacionados a este resultado, entre eles, a presença de tanino, que, segundo LASCANO e CARULLA (1992), pode reduzir, consideravelmente, a digestibilidade da fibra. O tanino liga-se às enzimas bacterianas e/ou forma complexos indigestíveis com carboidratos da parede celular, conseqüentemente, a atividade dos microrganismos celulolíticos é reduzida (REED, 1995). Outra atribuição está relacionada à maior concentração de lignina e sílica, em porcentagem da FDN, que, segundo MINSON (1990), pode resultar em decréscimo da digestibilidade e, por último, ao acréscimo do conteúdo de lipídeos nos tratamentos que continham FC em sua composição. ZEOULA et al. (1994), estudando os parâmetros de fermentação e o grau de degradabilidade ruminal da MS, PB e FDN de fenos de leguminosas e gramíneas em ovinos alimentados com dois níveis de lipídeos (3,7 e 7,8\%), verificaram maior potencial da FDN degradável no rúmen dos animais alimentados com a ração que apresentava menor teor de lipídeos. Os lipídeos podem também afetar a digestibilidade da fração fibrosa, por formarem camadas sobre a superfície de contato das mesmas, impedindo maior ataque dos microrganismos (Tamminga, citado por VASCONCELOS, 1997). Contudo, a presença do tanino parece melhor explicar estes resultados.

\section{Conclusões}

O feno de catingueira apresentou valor nutritivo e consumo voluntário, que permitem considerá-lo como um recurso de uso estratégico no período seco.

A adição do feno de catingueira à dieta diminuiu a digestibilidade dos constituintes da fração fibrosa.

As digestibilidades da MS e MO foram baixas, decorrentes, principalmente, da natureza lignificada do material utilizado.

Estudos são necessários com material colhido em outras fenofases.

\section{Referências Bibliográficas}

ARAÚJO FILHO, J.A., CARVALHO, F.C., GADELHA, J.A. et al. Fenologia e valor nutritivo de espécies lenhosas caducifólias da caatinga. In: REUNIÃO ANUAL DA SOCIEDADE BRASILEIRA DE ZOOTECNIA, 35, 1998, Botucatu. Anais... Botucatu: SBZ, 1998. p.360-362.

ARAÚJO FILHO, J.A., SILVA, N.L. Alternativas para o aumento da produção de forragem na caatinga. In: SIMPÓSIO NORDESTINO DE ALIMENTAÇÃO DE RUMINANTES, 5, 1994, Salvador. Anais... Salvador: SNPA, 1994, p.121-133. 
ARAÚJO, E.C., SILVA, V.M., VIEIRA, M.E.Q. et al. Valor nutritivo e consumo voluntário de forrageiras nativas da região semi-árida do Estado de Pernambuco. I. orelha de onça (Macroptilium martii (Benth) Marechal e Baudet). In: SIMPÓSIO NORDESTINO DE ALIMENTAÇÃO DE RUMINANTES, 5, 1994, Salvador. Anais... Salvador: SNPA, 1994. p.171.

ARAÚJO, E.C., SILVA, V.M., VIEIRA, M.E.Q. et al. 1997. Valor nutritivo e consumo voluntário de forrageiras nativas da região semi-árida do Estado de Pernambuco. II. Camaratuba (Cratylia mollis, Mart.). Pesq. Agropec. Pernambucana, 10(especial):131-135.

ARAÚJO, E.C., SILVA, V.M., VIEIRA, M.E.Q. et al. Valor nutritivo e consumo voluntário de forrageiras nativas da região semi-árida do Estado de Pernambuco. VII. Maniçoba (Manihot epruinosa Pax and Hoffmann). In: SIMPÓSIO NORDESTINO DE ALIMENTAÇÃO DE RUMINANTES, 6, 1996, Natal-RN. Anais... Natal: SNPA, 1996. p.194.

AGRICULTURAL RESEARCH COUNCIL - ARC. 1980. The nutrient requirements of ruminant livestock. London: Commonwealth Agricultural Bureaux. 351p.

BARROS, N.N., SOUSA, F.B., ARRUDA, F.A.V. 1997. Utilização de forrageiras e resíduos agroindustriais por caprinos e ovinos. Sobral: EMBRAPA/CNPC. 28p. (Documentos, 26).

BRAGA, R. 1960. Plantas do Nordeste, especialmente do Ceará. 2.ed. Fortaleza: Imprensa Oficial. 540p.

CARNEIRO, J.C., RODRIGUEZ, N.M. Digestibilidade aparente e balanço de nitrogênio da palha de soja em ovinos e caprinos. In: REUNIÃO ANUAL DA SOCIEDADE BRASILEIRA DE ZOOTECNIA, 33, 1996, Fortaleza. Anais... Fortaleza: SBZ, 1996. p.54-56.

LASCANO, C.E., CARULLA, J. Quality evaluation of tropical leguminous trees and shrubs with tannins for acid soils. In: SIMPÓSIO INTERNACIONAL EM RUMINANTES, 1992, Lavras. Anais... Lavras: SBZ, 1992. p.108-129.

LIMA, J.L.S. 1996. Plantas forrageiras da caatinga - usos e potencialidades. Petrolina: EMBRAPA/CPATSA/PNE/ RBG-KEW. 44p.

MAGALHÃES, P.C., RODRIGUES, W.A., DURÃES, F.O.M. 1997. Tanino no grão de sorgo - bases fisiológicas e métodos de determinação. Sete Lagoas: EMBRAPA - CNPMS. 26p. (EMBRAPA - CNPMS. Circular Técnica, 27).

MERTENS, D.R. Analysis of fiber in feeds and its uses in feed evaluation and ration formulation. In: SIMPÓSIO INTERNACIONAL EM RUMINANTES, 1992, Lavras. Anais... Lavras: SBZ, 1992. p.1-34.

MINSON, D.J. 1990. Forage in ruminant nutrition. San Diego: Academic Press Inc. 483p.

NARJISSE, H., ELHONSALI, M.A., OLSEN, J.D. 1995. Effects of oak (Quercus ilex) tannins on digestion and nitrogen balance in sheep and goats. Small Rum. Res., 18(2): 201-206.

NATIONAL ACADEMY OF SCIENCE - NAS. 1977. Nutrient requirement. Washington, D.C. $62 \mathrm{p}$.

NATIONAL RESEARCH COUNCIL - NRC. Nutrient requirements of sheep. 1985. Washington: National Academy of Sciences.

PEREIRA, V.L.A. Valor nutritivo do "mulch" e do feno de sabiá (Mimosa Caesalpiniifolia Benth.) inerme e com acúleos. Fortaleza, CE: UFC, 1998. 67p. Dissertação (Mestrado em Zootecnia) - Centro de Ciências Agrárias/Universidade Federal do Ceará, 1998.
PEREIRA, V.L.A., AZEVEDO, A.R., LIRA, M.A. et al. Composição químico-bromatológica do "Mulch"e do feno de sabiá (Mimosa caesalpiniifolia BENTH), inerme e com acúleo. In: REUNIÃO ANUAL DA SOCIEDADE BRASILEIRA DE ZOOTECNIA, 35, 1998, Botucatu. Anais... Botucatu, 1998. p.666-668.

REED, J.D. 1995. Nutritional toxicology of tannins and related polyphenols in forage legumes. J. Anim. Sci., 73(4):1516-1528.

RESENDE, F.D., QUEIROZ, A.C. Fibra em detergente neutro cersus fibra em detergente ácido na formulação de dietas para ruminantes. In: REUNIÃO ANUAL DA SOCIEDADE BRASILEIRA DE ZOOTECNIA, 31, 1994, Maringá. Anais... Maringá: SBZ, 1994. p.475.

SEOANE, J.R., CHRISTEN, A.M., VIEIRA, D.M. et al. Performance of growing steers fed quackgrass hay supplemented with canola meal. J. Anim. Sci., 72(2):329-336, 1992.

SILVA, A.M.A., PEREIRA FILHO, J.M., SOUZA, I.S. et al. Aceitabilidade por ovinos a espécies lenhosas do semi-árido paraibano. In: REUNIÃO ANUAL DA SOCIEDADE BRASILEIRA DE ZOOTECNIA, 35, 1998, Botucatu. Anais... Botucatu: SBZ, 1998, p.230-232.

SILVA, D.J. 1990. Análise de alimentos: métodos químicos e biológicos. 2.ed. Viçosa: UFV. 166p.

VASCONCELOS, V.R. Caracterização química e degradação deforrageiras do semi-árido brasileiro no rúmen de caprinos. Jaboticabal, SP: UNESP, 1997. 132p. Tese (Doutorado em Zootecnia) - Faculdade de Ciências Agrárias e Veterinárias/ Universidade Estadual Paulista, 1997.

VIEIRA, E.L., SILVA, A.M.A., COSTA, R.G. et al. Valor nutritivo do feno de espécies lenhosas da caatinga. In: REUNIÃO ANUAL DA SOCIEDADE BRASILEIRA DE ZOOTECNIA, 35, 1998, Botucatu. Anais... Botucatu: SBZ, 1998. p.227-229.

ZEOUlA, L.M. DEMITO, A., CECATO, U. et al. Degradabilidade "in situ" de gramíneas e leguminosas com diferentes níveis de lipídeos na ração de ovinos. In: REUNIÃO ANUAL DA SOCIEDADE BRASILEIRA DE ZOOTECNIA, 31, 1994, Maringá. Anais... Maringá: SBZ, 1994. p.503.

ZONTA, E.P., MACHADO.A.A. 1991. SANEST - Sistema de Análises Estatísticas. Campinas: IAC. 48p.

Recebido em: 19/04/00

Aceito em: 17/10/00 